BLS 32, No 1 2006. DOI: http://dx.doi.org/10.3765/bls.v32i1.3455 (published by the Berkeley Linguistics Society and the Linguistic Society of America)

\title{
Tonal and Morphological Identity in Reduplication
}

\author{
AARON F. KAPLAN* \\ University of California, Santa Cruz $^{1}$
}

\section{Introduction}

Chichewa is the only Bantu language in which verbal reduplication copies tones as well as segments (Hyman and Mtenje 1999). Some examples of this are given in (1). All Chichewa data are from Myers and Carleton (1996). Where such information is available, the morpheme that contributes the high tone in each nonreduplicated example is bolded.

$$
\begin{aligned}
& \text { a. tambalal-á } \\
& \text { tambalalá-tambalalá } \\
& \text { b. phik-its-á } \\
& \text { phikitsá-phikitsá } \\
& \text { c. ndíma-sangalátsa } \\
& \text { ndíma-sangalátsa-sangalátsa } \\
& \text { d. ti-sangalats-é } \\
& \text { ti-sangalatsé-sangalatsé }
\end{aligned}
$$

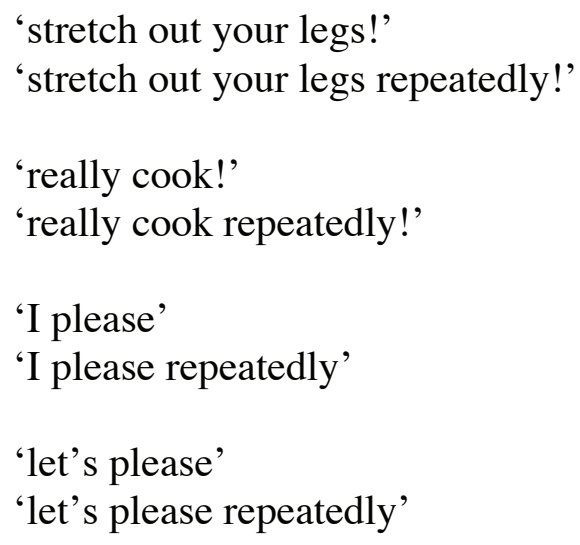

A successful analysis of Chichewa must produce matching tonal patterns in the two copies. This paper argues that tonal identity in Chichewa is a consequence of the language's general morphological properties, not reduplication-specific tone-placement constraints. Tone placement in verb stems is morphologically controlled (see below), so if we require morphological identity between bases and reduplicants (cf. Downing 1997a,b,c), the morphology will assign the same tonal patterns to the two copies. As reduplicative patterns in other languages

* Thanks to Carlos Gussenhoven, Larry Hyman, Abby Kaplan, Junko Itô, Anya Lunden, Armin Mester, Jaye Padgett, and participants in the UCSC Phonology Reading Group and the Stanford Phonology Workshop for their valuable comments throughout the development of this paper.

${ }^{1}$ Note: 2006 affiliation. Affiliation as of publication: University of Utah. 
Aaron F. Kaplan

demonstrate, the power to produce morphological identity is independently necessary.

The analysis below is couched in BR-Faithfulness (McCarthy and Prince 1995), but the same arguments hold within a theory like Morphological Doubling Theory (MDT; Inkelas and Zoll 2005), where morphological identity between the base and reduplicant follows from the fact that reduplication involves two instances of a set of morphemes. An MDT analysis requires the construction of three cophonologies (one for each copy and a third for the whole form) and is not pursued here because space considerations don't permit an analysis of this complexity. See also Pater (2007) for arguments against cophonologies in general and Urbanczyk (2006) for arguments against MDT specifically.

The paper is organized as follows: section 1 shows the need for morphological identity in Adhola (1.1) and Ndebele (1.2). Section 2 extends the analyses required for these languages to Chichewa. Section 3 summarizes the results.

\section{Morphological Identity under Reduplication}

\subsection{Adhola}

In verbal reduplication in Adhola, a Nilotic language spoken in Uganda, some morphemes copy obligatorily to the exclusion of other morphemes (cf. Kinande (Mutaka and Hyman 1990)). Adhola has two tones, high (H) and low (L), and there is a two-way tonal contrast between high-toned and low-toned verbs. (2) and (3) illustrate the basic reduplicative pattern with maximally disyllabic words. All Adhola data are from my notes from a field methods course taught at UC Berkeley in the fall of 2005 . Reduplicants are underlined throughout. L is not marked, and $y$ is a palatal glide.

\section{(2) Low-Toned CV, CVC, and CVCV Verbs}

\begin{tabular}{lllll} 
Verb & $3 s g$ Perfect & 'he Xed too much' & Future & 'he will X too much' \\
\hline kwot 'swell' & go kwot & go kwota-kwótâ & go lâ: kwot go lâ: kwota-kwótâ \\
tho 'die' & go tho & go tha-thâ & go lâ: tho go lâ: tha-thâ \\
yiko 'bury' & go yiko & go yika-yíkâa & go lâ: yiko go lâ: yika-yíkâ \\
tiyu 'work' & go tiyu & go tiya-tíyâ & go lâ: tiyu & go lâ: tiya-tíyâa \\
kayo 'bite' & go kayo & go kayo-káyâa & go lâ: kayo go lâ: kaya-káyâa
\end{tabular}

\section{(3) High-Toned CV, CVC, and CVCV Verbs}

\begin{tabular}{|c|c|c|c|c|}
\hline Verb & 3sg Perfect & 'he Xed too much' & Future & 'he will X to \\
\hline goré 'fight' & go & go gor & brê & go \\
\hline getó 'buil & & & & J \\
\hline Semó ‘ & go t temó & 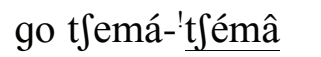 & go lâ: & go lấ \\
\hline
\end{tabular}


Reduplication is segmentally total, and the reduplicant seems to have a fixed $\mathrm{H}-\mathrm{HL}$ pattern. A suffix /-a/ whose identity is unclear to me appears in both copies, replacing any stem-final vowel. ${ }^{2}$ This suffix appears only in reduplicated forms.

Longer verbs are shown in (4) and (5). Long monomorphemic verbs cannot be reduplicated at all, regardless of the tone pattern. Polymorphemic verbs, though, can be reduplicated. The verbs in (5) contain the reflexive suffix /-ع́ré/, and in the reduplicated forms of these verbs, this suffix is eliminated from the second copy.

\section{(4) Long Monomorphemic Verbs}

\begin{tabular}{lll} 
Verb & 3 s Perfect & 'he Xed too much' \\
\hline nindirok 'beget' & *nindira-nindira \\
kí-siamula 'sneeze' go yasimulá & *yasimula-yasimula, *yasimula-mula \\
kí-símúlá 'wipe' & *simula-simula, *simula-mula, \\
& *simu-simula
\end{tabular}

\section{(5) Long Polymorphemic Verbs}

\begin{tabular}{lllll} 
Verb & $3 s g$ Perf. & Perf. Redup. & 3sg Future & Fut. Redup. \\
\hline yikéré 'prepare oneself’ & go yikéré & yikéré-!yíkâ & go lâ: yikéré & yikérá-!yíkâ \\
rukéré 'be dressed' & go rukéré & rukérâ-!rúkâ & &
\end{tabular}

These data point to two restrictions on reduplication. The entire root must be copied, and the reduplicant is maximally disyllabic. Where these requirements conflict, reduplication is impossible, as in (4) (cf. the Morpheme Integrity Constraint (Mutaka and Hyman 1990), MDep (Downing 1997b,c)). The verbs in (5) can be reduplicated because the stem can be adequately truncated by removing only the suffix, leaving the root intact. Of course, the forms in (2) and (3) can be reduplicated because the stems are short enough to begin with.

The root-copying and disyllabic requirements are enforced with MAX(Root)$\mathrm{BR}$ (6) and RED=FOOT $\sigma \sigma(7)$, respectively. RED $=\mathrm{FOOT}_{\sigma \sigma}$ stands in for principled constraints that produce a disyllabic reduplicant; see McCarthy and Prince (1995), Spaelti (1997), Kennedy (2005).

(6) $\operatorname{MAx}($ Root)-BR: Every root segment in the base stands in correspondence with some segment in the reduplicant.

(7) $\mathrm{RED}=\mathrm{FOOT}_{\sigma \sigma}$ : The reduplicant is a disyllabic foot.

2 The stem-final vowel may be a suffix itself (see discussion of (4) and (5)), or its deletion may be the result of a more general hiatus resolution strategy seen elsewhere in Adhola. 
Ranked over MPARSE (Prince and Smolensky 1993), these constraints prevent reduplication of long monomorphemic words (8). The reduplicant in candidate (a) is disyllabic, but $\operatorname{MAX}(\mathrm{Root})-\mathrm{BR}$ is fatally violated: not all root segments are copied. Candidate (b) copies the entire root but fatally violates RED $=\mathrm{FOOT}_{\sigma \sigma}$. The null parse wins because it violates only the lowest-ranked MPARSE.

\begin{tabular}{|c|c|c|c|}
\hline$/$ /nindirok RED/ & MAX(Root)-BR & RED=FOOT $_{\sigma \sigma}$ & MPARSE \\
\hline a. nindira-ninda & $* !$ & & \\
\hline b. nindira-nindira & & $* !$ & \\
\hline c. $\varnothing$ & & & $*$ \\
\hline
\end{tabular}

Long polymorphemic verbs can be reduplicated (9). The truncation candidate (candidate (a)) avoids a violation of MAX(Root)-BR because the deleted segments belong to the suffix. Only the low-ranked MAX-BR is violated. Candidate (b), with full copying, loses because of a RED=FOOT ${ }_{\sigma \sigma}$ violation, and the null parse is suboptimal because MPARSE outranks MAX-BR.

(9)

\begin{tabular}{|l|c:c|c|c|}
\hline /yik-ćré RED/ & MAX(Root)-BR & RED=FOOT $_{\sigma \sigma}$ & MPARSE & MAX-BR \\
\hline a. yikéré-'yíkâa & & & & $*$ \\
\hline b. yikérá-'yikérâ & & $* !$ & & \\
\hline c. $\varnothing$ & & & $* !$ & \\
\hline
\end{tabular}

To my knowledge, there are no roots (that can appear with /-Éré/) short enough to show whether suffixes may be copied if there is room for them in the reduplicant's disyllabic window. Likewise, there are no verbal prefixes.

Adhola shows that reduplication can be sensitive to the morphology of its base. Templatic requirements are balanced with morphological requirements so that the disyllabic reduplicant contains all of base's root segments, while suffixes are expendable. $\operatorname{MAX}($ Root)-BR imposes a measure of morphological identity on the two copies by ensuring that they contain identical strings of root segments.

\subsection{Ndebele}

Ndebele (Hyman et al. 2003) also shows morphological influence on reduplication. As a Bantu language, Ndebele has the verbal structure shown in (10), adopting the terminology of Hyman et al. (2003). 
(10)

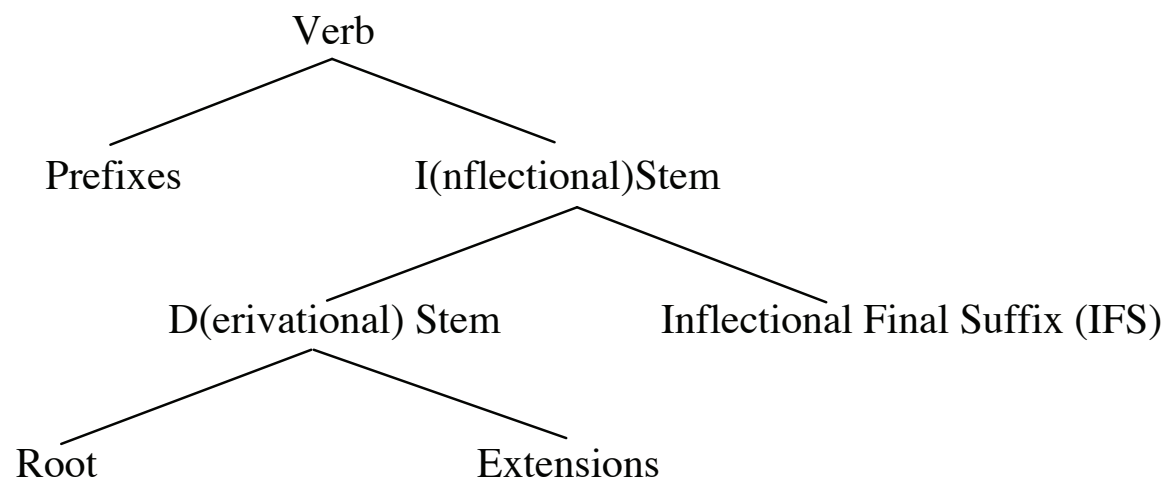

In Ndebele verbal reduplication, the root must be copied, extensions may be copied, and the IFS cannot be copied. The reduplicant is a prefix and maximally disyllabic (Hyman et al. 2003). (11) shows that extensions can optionally be copied. Two reduplicants are possible for these forms, and the bold face vowels are copies of the extensions' vowels. The roots (which are initial in each stem) are copied completely, and the disyllabic template leaves room for only one segment from the extensions.
a. lim-el-a

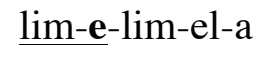
'cultivate for/at'
b. lim-is-a
lim-a-lim-el-a
$\underline{\text { lim-i-lim-is-a }}$
'make cultivate'

The alternative forms in (11) seem to show copying of the IFS, but (12) shows that this $a$ is really epenthetic. When the IFS contains a different vowel, this vowel cannot be reduplicated. The apparent IFS copying in (11) is instead insertion of a default vowel that happens to be phonologically identical to the IFS.
a. lim-e
lim-a-lim-e
'cultivate (subjunctive)'
*lim-e-lim-e
b. lim-i
lim-a-lim-i
'not cultivate'
c. lim-ile
*lim-i-lim-i
'cultivate (perfective)'
*lim-i-lim-ile

(13) shows further that non-root segments may appear in the reduplicant only if the root doesn't fill the disyllabic template. The epenthetic $a$ is banned if it would take the place of a root segment. These data motivate the ranking $\operatorname{MAX}\left(\right.$ Root)-BR $>$ MAX(Non-Root)-BR. ${ }^{3}$

3 This follows the metaranking Root-Faith >> Affix-Faith (McCarthy and Prince 1995:116). The general MAX constraint could be adopted instead of the affix-specific version (as in the analysis of Adhola above). 
Aaron F. Kaplan

(13)
a. casul-a casu-casul-a
'nauseate (tr.)'
*cas-a-casul-a
b. nambith-a nambi-nambith-a 'taste'
*namb-a-nambith-a
c. thembuz-a thembu-thembuz-a 'go from wife to wife'
*themb-a-thembuz-a

The disyllabic template takes precedence over root copying: the root is truncated if it is longer than two syllables. The ranking $\mathrm{RED}=\mathrm{FOOT}_{\sigma \sigma}>$ MAX(Root)-BR produces this effect. Like Adhola, root segments must be copied, but here, the inability to copy the entire root does not cause ungrammaticality. The rankings motivated so far are illustrated in (14). ${ }^{4}$ Candidate (b) loses because it violates the high-ranking $\mathrm{RED}=\mathrm{FOOT}_{\sigma \sigma}$. The winner satisfies this constraint, violating both MAX constraints but producing a disyllabic reduplicant.

\begin{tabular}{|c|c|c|c|}
\hline$/$ RED nambith-a/ & RED=FOOT $_{\sigma \sigma}$ & MAX(Root)-BR & MAX(Non-Rt)-BR \\
\hline a. nambi-nambith-a & & $*$ & $* *$ \\
\hline b. nambith-a-nambith-a & $* !$ & & \\
\hline
\end{tabular}

The reduplicant is a DStem (Hyman et al. 2003): it can contain roots and extensions, but not IFSs. The constraints below account for this: (15) requires reduplicants to be DStems, and (16) prevents DStems from containing IFSs. As with $\mathrm{RED}=\mathrm{FOOT}_{\sigma \sigma}, \mathrm{RED}=\mathrm{DSTEM}$ is a cover for more principled constraints.

\section{RED=DSTEM: Reduplicants are DStems.}

*DSTEM IFS: DStems may not contain IFSs.

The inability of IFSs to be copied seems to be accounted for. Candidate (b) in (17) violates either RED=DSTEM or *DSTEM IFS, depending the morphological bracketing: either the reduplicant is a DStem and *DSTEM IFS is violated, or it is not a DStem and RED=DSTEM is violated. Either way, the IFS cannot be copied.

(17)

\begin{tabular}{|c|c|c|c|c|c|}
\hline /RED lim-i/ & $\mathrm{RED}=\mathrm{FOOT}_{\sigma \sigma}$ & RED=DSTEM & *DSTEM IFS & MAX(Non-Rt) & DEP \\
\hline a. lim-a-lim-i & & & & $*$ & * \\
\hline 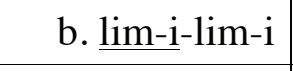 & & $(* !)$ & $(* !)$ & & \\
\hline c. $\underline{\lim -\lim -\mathrm{i}}$ & $* !$ & & & $*$ & \\
\hline
\end{tabular}

4 The candidate *nambith + nambith- $a$ is ruled out by constraints on codas. 
But candidate (b) loses only if the copy of the IFS retains the morphological status of the IFS. The problem with *lim-i-lim-i lies in its illicit morphological configuration, but it doesn't violate *DSTEM IFS if the reduplicant-final $i$ is not morphologically an IFS. We therefore need a constraint like the one in (18).

IDENT(Morphological Affiliation)-BR (IDENT(Morph)): Corresponding segments in the base and reduplicant have identical morphological affiliations. (cf. Downing 1997a,b,c)

This constraint requires corresponding segments to be "marked" as belonging to the same morpheme. Just as we have constraints requiring the reduplicant-final $i$ in (17b) to copy the base vowel's [+high] and [-back] features, IDENT(Morph) requires $i$ to copy the base vowel's morphological affiliation; both segments must be marked as belonging to an IFS. This constraint lets us rule out the interpretation of (17b) in which the reduplicant is a DStem but the reduplicantfinal $i$ is not formally an IFS:

\begin{tabular}{|c|c|c|c|c|c|c|}
\hline /RED lim-i/ & $\begin{array}{c}\text { IDENT } \\
\text { (Morph) }\end{array}$ & $\begin{array}{l}\text { RED }= \\
\text { FOOT }\end{array}$ & $\begin{array}{c}\text { RED }= \\
\text { DSTEM }\end{array}$ & $\begin{array}{c}* \text { DSTEM } \\
\text { IFS }\end{array}$ & $\begin{array}{l}\text { MAX(Non- } \\
\text { Root) }\end{array}$ & $\begin{array}{c}\text { DEP- } \\
\text { BR }\end{array}$ \\
\hline a. lim-a-lim-i & & & & & $*$ & $*$ \\
\hline 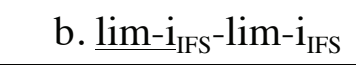 & & & & $* !$ & & \\
\hline 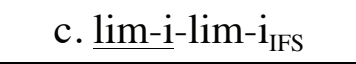 & $* !$ & & & & & \\
\hline
\end{tabular}

Subscripts mark the relevant segments' morphological affiliations. Only candidates that satisfy RED=DSTEM are considered. The copies in candidate (b) are phonologically and morphologically identical. Crucially, the final vowel in each copy is an IFS. This satisfies IDENT(Morph) but fatally violates *DSTEM IFS because the reduplicant's DStem contains an IFS. In candidate (c), the reduplicant-final vowel is not formally an IFS. *DSTEM IFS is not violated, but IDENT(Morph) is now violated because the reduplicant-final vowel does not bear the same morphological affiliation as its base counterpart. Candidate (a) avoids the problem by filling out the disyllabic template with an epenthetic vowel instead of a copy of the IFS. Only the low-ranking MAX(Non-Root) and DEP are violated.

A segment's ability to be reduplicated can depend on its morphological status. In both Adhola and Ndebele, roots are preferentially copied over affixes. More importantly, Ndebele shows that in some cases, reduplication must copy segments' morphological affiliations. In the next section, the constraints motivated above are adopted to account for tonal identity in Chichewa reduplication. 


\section{IDENT(Morph) and Tonal Identity}

Recall that verbal reduplication in Chichewa is segmentally and tonally total. In non-reduplicated verbs, $\mathrm{H}$ that comes from a morpheme in the IStem appears on one of the last two syllables of the IStem (marked below with square brackets): $\mathrm{H}$ from the root, an extension, or the subjunctive marker falls on the final syllable, and Hs from other morphemes surface on the penultimate syllable. (20) and (21) account for these tones. ${ }^{5}$ (Tones from prefixes can appear on the stem-initial syllable - ndi-na-sángalats-a 'I pleased' - but these tones aren't analyzed here.)

(20) $\operatorname{Align}(H, R$, IStem, R) (Align-R): The right edge of every high tone span is aligned with the right edge of some IStem.

(21) NonFinality (NonFin): H from a non-root, non-extension, and nonsubjunctive morpheme does not appear on the final Tone-Bearing Unit (TBU) of a stem.

(22) and (23) show how these constraints produce final and penultimate tone placement, respectively. The morpheme that contributes the high tone is bolded in the input, and tones that are subject to NONFIN are italicized. (23) shows the necessity of the ranking NONFIN $>$ ALIGN-R.

\section{(22) H on Final Syllable}

\begin{tabular}{|c|c|c|}
\hline /tambalal-a H/ & NonFIN & ALIGN-R \\
\hline a. [támbalala] & & $* ! * *$ \\
\hline b. [tambalála] & & $* !$ \\
\hline$\approx$ c. $[$ tambalalá] & & \\
\hline
\end{tabular}

(23) H on Penultimate Syllable

\begin{tabular}{|c|c|c|}
\hline /ndí-ma- $\boldsymbol{H}$-sangalats-a/ & NONFIN & ALIGN-R \\
\hline a. ndíma-[sangálatsa] & & $* ! *$ \\
\hline b. ndíma-[sangalátsa] & & $*$ \\
\hline c. ndíma-[sangalatsá] & $* !$ & \\
\hline
\end{tabular}

Reduplicants in Chichewa are IStems: roots, extensions, and IFSs are copied. With the base and reduplicant each an IStem, there are two boundaries with which tones can align. When the base's tone is not subject to NonFIn, identical tone placements are produced with the existing constraints (24), as long as $\operatorname{MAX}(\mathrm{H})$ BR forces tone copying. Candidate (b) in (24) loses because the reduplicant's tone

5 An analysis that takes penultimate placement to be default and uses a morpheme-specific ALIGN-R (rather than a morpheme-specific NONFIN) is equally plausible. 
is misaligned, whereas in candidate (c), both tones are at the right edge of some IStem. In the absence of evidence, I assume the first copy is the reduplicant.

\begin{tabular}{|c|c:c|c|}
\hline$/$ RED tambalal-a H/ & MAX $(\mathrm{H})-\mathrm{BR}$ & NONFIN & ALIGN-R \\
\hline a. [tambalala]-[tambalalá] & $* !$ & & \\
\hline b. [tambalála]-[tambalalá] & & & $* !$ \\
\hline c. [tambalalá]-[tambalalá] & & & \\
\hline
\end{tabular}

However, (24) produces the right output because right alignment is the default pattern. When the base's tone is penultimate, the constraints still produce final tone placement in the reduplicant:

(25)

\begin{tabular}{|c|c|c|c|}
\hline /RED ndí-ma- $\boldsymbol{H}$-sangalats-a/ & MAX(H)-BR & NONFIN & ALIGN-R \\
\hline * $^{*}$ a. ndíma-[sangalatsá]-[sangalátsa] & & & $*$ \\
\hline$\left(\sigma^{\circ}\right.$ b. ndíma-[sangalátsa]-[sangalátsa] & & & $* * !$ \\
\hline
\end{tabular}

Since formally only the base's tone comes from a morpheme that is subject to NonFIn, final placement of the reduplicant's tone does no harm. Alternatively, on the assumption that RED is subject to NONFIN, the wrong result for (24) is predicted: *[tambalála]-[tambalalá]. In short, the analysis currently has no way to produce anything but the default tone pattern on the reduplicant.

IDENT(Morph) solves this problem. By requiring morphological identity between base and reduplicant tones, we can capture the insight that the reduplicant's tonal configuration is ultimately dependent on the morphological composition of the base. In (26), IDENT(Morph) requires both tones to be marked as belonging to the root (as indicated by subscripts on their host vowels), and consequently they are both exempt from NonFIN. The two tones are at the right edge of their respective IStems in the optimal candidate.

\begin{tabular}{|c|c|c|c|c|}
\hline /RED tambalal-a H/ & IDENT(Morph) & $\operatorname{MAX}(\mathrm{H})$ & NONFIN & AliGN-R \\
\hline a. [tambalalá $\left.{ }_{R t}\right]-\left[\right.$ tambalalá $\left._{\mathrm{Rt}}\right]$ & & & & \\
\hline b. [tambalalá]-[tambalalá $\left.{ }_{\mathrm{Rt}}\right]$ & $* !$ & & & \\
\hline c. [tambalala]-[tambalalá Rt $]$ & & $* !$ & & \\
\hline d. [tambalá $\left.{ }_{\mathrm{Rt}} \underline{\text { la }]-[\text { tambalalá }}{ }_{\mathrm{Rt}}\right]$ & & & & $* !$ \\
\hline
\end{tabular}


The more interesting case is (27); for space, only the IStem from (1c) is shown. IDENT(Morph) ensures that the reduplicant tone copies the morphological affiliation of the base tone. It is therefore subject to NONFIN and appears on the penultimate syllable of its IStem. IDENT(Morph) rules out candidate (b) because the reduplicant's tone doesn't retain the morphological affiliation of the base's tone. Candidate (c) loses because the tone fails to copy. Candidate (d) copies the tone and its morphological affiliation, but NONFIN penalizes the reduplicant tone's placement. Candidate (a) wins: the reduplicant's tone has the same morphological marking as the base's tone, and both tones satisfy NoNFIN.

\begin{tabular}{|c|c|c|c|c|}
\hline /RED $\boldsymbol{H}$-sangalats-a/ & IDENT(Morph) & $\operatorname{MAX}(\mathrm{H})$ & NONFIN & ALIGN-R \\
\hline 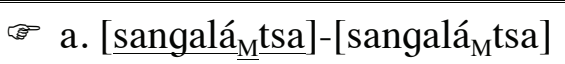 & & & & $* *$ \\
\hline b. [sangalátsa]-[sangalá ${ }_{\mathrm{M}}$ tsa] & $* !$ & & & $* *$ \\
\hline c. [sangalatsa]-[sangalá $\left.{ }_{\mathrm{M}}^{\mathrm{tsa}}\right]$ & & $* !$ & & * \\
\hline d. [sangalatsá $\left.\underline{M}_{M}\right]-\left[\right.$ sangalá $\left._{\mathrm{M}} \mathrm{tsa}\right]$ & & & $* !$ & * \\
\hline
\end{tabular}

The morphological faithfulness constraint that was motivated by Ndebele provides an account of tonal identity in Chichewa reduplication. This analysis doesn't compare corresponding tones' placements or require corresponding TBUs to bear identical tones. Tonal identity is instead a consequence of morphological faithfulness and the morphologically driven tone-placement system of Chichewa.

Finally, disyllabic and shorter stems in Chichewa do not show tonal identity:

$$
\begin{aligned}
& \text { a. ndíma-óna 'I see' } \rightarrow \quad \text { ndíma-ona-óna 'I see repeatedly' } \\
& \text { b. ndíma-dyá 'I eat' } \rightarrow \text { ndíma-dya-dyá 'I eat repeatedly' }
\end{aligned}
$$

I suggest that this reflects IStem minimality requirements. The reduplicant is too short to form its own IStem, so the two copies form an IStem together. With only one IStem, the base and reduplicant tones must both appear on one of the last two syllables of the reduplicant + base unit, depending on the relevance of NONFIN.

\section{Conclusion}

I have argued for a constraint whose effect is to create identical morphological configurations under reduplication. IDENT(Morph) requires corresponding elements to have the same morphological affiliation: if one segment belongs to morpheme $\mathrm{M}$, its correspondent must also be a member of $\mathrm{M}$. This constraint was motivated by Ndebele, building on an investigation of Adhola. Segments in these languages reduplicate or not according to their morphological properties. In Ndebele, IDENT(Morph) prevented copying of IFSs, and in Chichewa it ensured that base and reduplicant tones were treated the same way by the tone-placement constraints. Tonal identity in Chichewa is the product of independently necessary 
morphological constraints. There is no need for a mechanism that keeps track of matching TBUs and their tonal affiliations in the two copies. Interestingly, in Chichewa, IDENT(Morph) promoted similarity between the base and reduplicant, while in Ndebele it inhibited similarity by blocking IFS copying and motivating epenthesis to fill the reduplicant's disyllabic template.

MDT has an advantage over BR-Faithfulness in that IDENT(Morph) is unnecessary in MDT. Reduplication involves two instances of exactly the same set of morphemes in MDT, so identical morphological configurations between the two copies is an automatic, unavoidable consequence (at the cost of requiring several cophonologies; see references given above). IDENT(Morph) is superfluous in MDT: "corresponding" (correspondence under reduplication is eliminated in MDT) elements in the two copies belong to the same morphemes from the start.

The analyses above rank IDENT(Morph) highly. The effect of a demoted IDENT(Morph) is illustrated in the predominant reduplication pattern in Bantu. In all languages except Chichewa (but see Downing (2003) for a different view), tones are not copied in verbal reduplication. The tonal pattern from the nonreduplicated form appears on the entire base + reduplicant unit. Tones at one edge of the unreduplicated stem appear at the same edge of the base + reduplicant unit. This is illustrated in (29) with examples from Kikerewe (Odden 1996).
a. ku-káláanga
'to fry'
ku-káláanga-kalaanga
'to fry any old way'
n-kalaangile-kalaangílé
'I fried off and on (yesterday)'
b. ku-bíba
ku-bíba-biba
'to plant'
'to plant here and there'
c. m-bazílé
'I counted (yesterday)'
m-bazile-bazílé
'I counted (yesterday) carelessly'

Tones align with an edge of the IStem, so the base + reduplicant unit must be an IStem, and the reduplicant must therefore be smaller than an IStem; it is maximally a DStem. But IFSs are copied. This means that the copy of the IFS must not be a morphological IFS, or else it would be banned from the reduplicant for the same reason as in Ndebele. Consequently, morphological identity must not hold between these vowels, meaning that IDENT(Morph) must be low-ranked.

\section{References}

Downing, Laura J. 1997a. Correspondence Effects in Siswati Reduplication. Studies in the Linguistic Sciences 25:81-95.

Downing, Laura J. 1997b. Morphological Correspondence in Kinande Reduplication. In Proceedings of Berkeley Linguistics Society, vol. 23:83-94. 
Aaron F. Kaplan

Downing, Laura J. 1997c. Morphological Correspondence on Kikerewe Reduplication. In Proceedings of WCCFL, vol. 16:161-174.

Downing, Laura J. 2003. Compounding and Tonal Non-Transfer in Bantu Languages. Phonology 20:1-42.

Hyman, Larry M., Sharon Inkelas, and Galen Sibanda. 2003. Morphosyntactic Correspondence in Bantu Reduplication. In K. Hanson and S. Inkelas, eds., The Nature of the Word: Essays in Honor of Paul Kiparsky, Cambridge, MA: MIT Press.

Hyman, Larry M. and Al Mtenje. 1999. Prosodic Morphology and Tone: The Case of Chichewa. In R. Kager, H. van der Hulst, and W. Zoonneveld, eds., The Prosody-Morphology Interface, 90-133, Cambridge: Cambridge University Press.

Inkelas, Sharon and Cheryl Zoll. 2005. Reduplication. Cambridge: Cambridge University Press.

Kennedy, Robert. 2005 The Binarity Effect in Kosraean Reduplication. Phonology 22:145-168.

McCarthy, John and Alan Prince. 1995. Faithfulness and Reduplicative Identity. In J. Beckman, L. W. Dickey, and S. Urbancyzk, eds., University of Massachusetts Occasional Papers in Linguistics 18: Papers in Optimality Theory, 149-348, Amherst, MA: GLSA Publications.

Mutaka, Ngessimo and Larry M. Hyman. 1990. Syllables and Morpheme Integrity in Kinande Reduplication. Phonology 7:73-120.

Myers, Scott and Troi Carleton. 1996. Tonal Transfer in Chichewa. Phonology 13:39-72.

Odden, David. 1996. Patterns of Reduplication in Kikerewe. OSU Working Papers in Linguistics 48:111-149.

Pater, Joe. 2007. The Locus of Exceptionality: Morpheme-Specific Phonology as Constraint Indexation. In L. Bateman, A. Werle, M. O'Keefe, and E. Reilly, eds., University of Massachusetts Occasional Papers in Linguistics 33: Papers in Optimality Theory III, Amherst, MA: GLSA Publications. 259-296.

Prince, Alan and Paul Smolensky 1993. Optimality Theory: Constraint Interaction in Generative Grammar. Ms., Rutgers University \& University of Colorado, Boulder Published 2004 Malden, MA and Oxford: Blackwell.

Spaelti, Philip. 1997. Dimensions of Variation in Multi-Pattern Reduplication. Ph.D. diss., University of California, Santa Cruz.

Urbanczyk, Suzanne. 2006. Reduplicative Form and the Root-Affix Asymmetry. Natural Language and Linguistic Theory 24:179-240.

Linguistics

Languages \& Communication Bldg.

255 S. Central Campus Dr. Rm. 2300

Salt Lake City, UT 84112-0492

aaron.kaplan@utah.edu 